\title{
An Empirical Approach and Implications for Teachers to Begin Constructivist Teaching
}

\author{
Xiaohong Zhang \\ School of English and Cultural Studies, Shanghai Art and Design Academy, Shanghai, China \\ Email: ziye815@163.com
}

How to cite this paper: Zhang, X.H. (2019) An Empirical Approach and Implications for Teachers to Begin Constructivist Teaching. Open Journal of Social Sciences, 7, 375-386.

https://doi.org/10.4236/jss.2019.710032

Received: October 18, 2019

Accepted: October 28, 2019

Published: October 31, 2019

\begin{abstract}
This paper aims to explore teachers' perceptions and views about the implementation of constructivist teaching from an empirical research in a vocational college classroom. Constructivism and constructivist teaching pedagogies are visited first to find the requirements as well as barriers for constructivist teachers. Both quantitative and qualitative data are collected from students surveyed with a questionnaire and teachers with interviews addressing the experiences and concerns of their teaching practice. Based on the data gathered, the teachers' desired teaching model, along with students' prospective feedback to the implementation of constructivist teaching is fully analyzed. By examining the students' identified needs and the teachers' perceptions, it is concluded that students' learning preferences links to constructivist ideas and teachers' teaching practice needs reforming and changing in order to undertake constructivist teaching.
\end{abstract}

\section{Keywords}

Constructivist Teaching, Student and Teacher Perspective, Empirical Research

\section{Introduction}

Constructivism, an epistemology offering an explanation of the nature of knowledge and how learners learn has been a key concept and gained increasingly influential popularity in philosophy and education [1] ever since its emergence in the early 18th century [2]. Different branches emerged as its evolution, but grounding assumptions [3] are generally agreed upon: 1) all knowledge is constructed and comes from constructivist activities in an individual's brain as a result of his or her own life experience; 2) knowledge is context dependent, so learning should occur in contexts to which it is relevant; 3) Learning is mediated 
by tools and signs; 4) knowing how we know is the ultimate human accomplishment.

Accordingly in the classroom, constructivist teaching requires a shift in teaching "from a telling-listening relationship to a complex and interactive relationship where the students' own effort to understand are the focal point." [4]. Building upon this belief, constructivist teaching is viewed as a "progressive" learning-teaching approach [5], by which learners find opportunities to become aware of their experience, build upon it, extend it and in the process create new experiences which become part of what they know [6]. The main teaching principles summarized by Muijis [5] are as follows:

- Learning is always an active process. Learning is about helping pupils construct their own meaning, not about getting the right answer, as pupils can be trained to get the right answer without actually understanding the concept.

- The construction of knowledge is not just an individual thing. Learning is socially constructed through interaction with peers, teachers and parents. So, it's best to construct the learning situation socially, by encouraging group work and discussion.

- Learning is always contextualized. We learn best when new learning is explicitly connected to what we already know.

- Real in-depth learning means thoroughly constructing knowledge, by exploring and revisiting material rather than quickly moving from topic to topic as in the direct instruction approach.

- Teaching is about empowering the learner, and allowing the learner to discover and reflect authentic learning and deeper understanding compared to the surface memorization that often characterizes other teaching approaches. It's better to use hand-on and real-life materials rather than textbooks.

\section{Theoretical Analysis of Constructivist Teaching}

\subsection{Comparison of Principles of Constructivist Teaching and Non-Constructivist Teachings}

As far as constructivist teaching and non-constructivist are concerned, there is a range of different research. According to Muijis [5], the basics of teaching and learning can be categorized into four main types, namely direct instruction, interactive teaching, collaborative small-group teaching and constructivist teaching. The former three are labeled as "traditional" and the latter one as "progressive". Although it will depend on what happens in each context in terms of the learning process as to whether this is the case. As Kim [7] concludes that "traditional instruction leads students to believe they are not interested in particular subject areas. The constructivist paradigm holds disinterest less as a function of a particular subject area than as a function of the ways in which students have been taught. The following table summarizes the differences between the four teaching approaches in the aspects of core value, main features, teaching effectiveness and limitations (see Table 1). 
Table 1. A look at the difference between constructivist teaching and non-constructivist teachings.

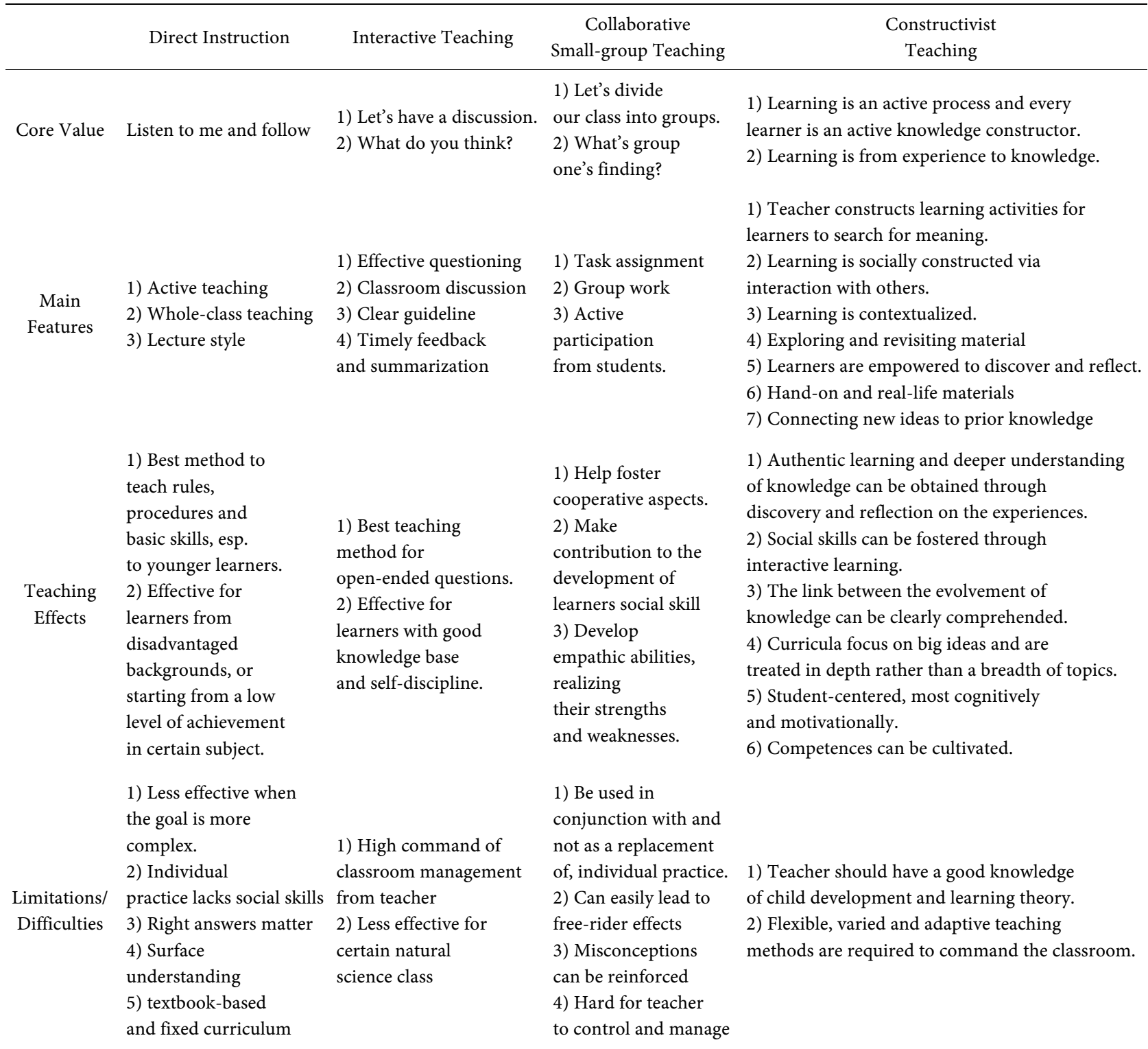

(adapted from Mujis et al., 2005).

\subsection{Constructivist Pedagogic Model}

Many constructivist researchers have interpreted their varied and subject-specific views on constructivist teaching strategies and methods. Schreiber et al. [8] focus on the constructivist teaching in the small group classroom, and discourse on five specific pedagogical techniques. Baviskar et al. [9] propose four essential criteria for Constructivist teaching, namely, 1) elicitation of prior knowledge, 2) creation of cognitive dissonance, 3) application of new knowledge with feedback, 4) reflection on learning. Moreover, they use them to test five "constructivist" teaching approaches raised in five papers on constructivist teaching methods, namely " $5 \mathrm{E}$ " model by Bybee [10], which is claimed as a constructivist teaching model, consisting of five phases: Engagement - Exploration - 
Explanation - Elaboration - Evaluation.

Engagement, the starting phase of the model, is designed to boost learner's attention, imagination and motivation in the introduction of a new topic [5]. With the deepening of students' understanding and motivation over time, when the students feel puzzled and highly challenged in inquiring and leaning, the engagement will ebb to facilitate next phase-exploration. Exploration works as the key aspect of the constructivist teaching by allowing learners to develop their thinking and meaning-making via two important approaches: coaching and reflection. Explanation gives learners the opportunity to articulate their ideas, thoughts and findings, which are closely linked to the prior engagement and exploration activities [11]. To enable them to express their deepened and sharpened understanding, multi-leveled tasks should be designed from a simple causal talk to the presentation in a formal setting, or even to an open public debate. Noticeably, group work works best for the students to explain by providing a preferable environment with more chances to communicate. Elaboration, another key phase in constructivist teaching and learning, offers learners the opportunity to extend their findings to other specific contexts. The essential element in this phase is to supply learners with choices and options. Rather than the teacher-designed assignments and tasks, students are motivated to offer more projects to further their thinking by themselves. This will not only facilitate their learning, but also bring more new learning. Evaluation, the final phase, refers to the formal assessment of students' learning and understanding. And the criterion of this assessment phase is to see whether the learner have attained the abilities to make the transition from knowing to understanding, such as contextualizing the knowledge, explaining in one's own words, generalizing into a broader context, justifying by offering evidence [12]. The result of the evaluation can be open or final, but the final phase can never be closing, because it marks a new loop of a deeper learning [5].

The Five Es Model can be applied in both individual lessons and serial-subjects, in both philosophical arts and technological science. As the oft-cited constructivist teaching practice, the model integrates aspects of five phases, and interestingly, each phase should be planned and implemented in a unit as a whole [11]. Constructivist teaching being as an progressive teaching approach with high achievement gains and teaching effectiveness, "many teachers are in favor of adopting constructivist instructional approaches but are unsure of where to begin" [6].

\subsection{The Roles and Concerns of Teachers in Constructivist Teaching}

Constructivist instruction requires sensitivity to all aspects of a situation in which learners structure their experience in its many different spheres. For teachers to handle effectively the challenge of a constructivist curriculum with confidence, it is essential for them to develop appropriate knowledge, skills and attitudes in constructivist teaching. It will allow teachers to make a smooth tran- 
sition from transmitters of knowledge to facilitators of learning for the learner's construction [13].

To realize the shift from the sage on the stage to the guide on the side, Petragila argues that in constructivist teaching, the teacher is best positioned "in the possibility of intervening the learning that is occurring, rather than being in charge of the act of learning" [14]. Besides, teachers are expected to build up a learning atmosphere as energizing, collaborative, immersive and informative as the life of student outside of 9:00-3:30 time slot [15]. Brooks and Brooks [16] suggest twelve strategies for teachers to exercise in order to move towards a more constructivist approach:

- encourage and accept student autonomy and initiative;

- use raw data and primary sources, along with manipulative, interactive, and physical materials;

- allow student responses to drive lessons, shift instructional strategies, and alter content;

- inquire about students' understanding of concepts before sharing their own under standings of those concepts;

- encourage students to engage in dialogue, both with the teacher and with one another;

- encourage student inquiry by asking thoughtful, open-ended questions and encouraging students to ask questions of each other;

- seek elaboration of students' initial responses;

- engage students in experiences that might engender contradictions to their initial hypotheses and then encourage discussion;

- allow wait time after posing questions;

- provide time for students to construct relationships and create metaphors. To be a constructivist teacher, a number of general factors have to be taken into account for the teaching effectiveness in general: 1) good subject knowledge; 2) good questioning skill; 3) an emphasis upon instruction; 4) a balance of grouping strategies; 5) clear objectives; 6) good time management; 7) effective planning; 8) good classroom organization; 9) effective use of teaching media. According to Chaille et al. [16] and Muijis [5], the roles of a teacher in a constructivist classroom, should be a researcher, a question asker, a coach, a professional team player, a presenter, an environment organizer, a facilitator, and an operator.

However, to teachers, a constructivist approach to teaching itself is viewed as "a challenge and a concept that is difficult to grasp in a short period of time" [13]. Dharmadasa summarizes challenges teachers face in constructivist classroom as much as follows:

- Constructivist mode of teaching demands a large amount of planning which is both time and energy consuming, and insufficient prior knowledge base for constructivist transmission prevented teachers from attempting the new curriculum. 
- Teachers need to use outside resources and materials such as hands-on objects, additional books, and computer programs and not rely solely on a textbook to enhance learners' learning. So teachers should be provided with knowledge how, where and when to access to these resources.

- The Constructivist approach to teaching and learning would hinder effective classroom management. The teachers are more concerned about assumed disciplinary problems and problems in classroom management than in creating supportive learning environments to learners. The classes, small in size, could promote effective teacher-learner interaction, but the ones of large number of students are very difficult to handle. The greatest challenge is to be prepared to ask probing questions that promote learners' thinking to higher levels.

Taking all the concerns into consideration, we can find the comments made by Cey reasonable and sensible without much wonder. "When observing the activities and behaviors of a constructivist teacher on any given day, one would notice the distinctive resemblance to the bounce of a prairie coyote that is warily and shrewdly making its way around its environment in a non-linear, yet purposeful, prepared and productive fashion" [6].

\section{Data Analysis and Findings}

After a clear theoretical structure was made, first-hand data would be collected by using questionnaires and interviews. 24 questionnaires were distributed to a class of first year in a vocational college. The main concerns in the questionnaire are: what makes good learning, the sources of knowledge and skills, how to begin a class, the effectiveness of learning activities, roles a teacher plays in the class, and the students' expectations of their ability. Besides, the main interviewees are one college teacher and one peer cohort student. To the peer student, a semi-structured interview was conducted under heading 'standardized interview' [17] at the end of the project. The main content is about their contrast and corresponding experiences of the traditional and Constructivist teaching they have had in college, and any comment, suggestion or advice for teaching practice will be invited as well. To the college teacher, a semi-structured interview and individual interview was adopted under heading "non-standardized interview" at the beginning of the project. The main content will be about their knowledge, learning tips and application of teaching approach. Experience related to how to get students engaged in the teaching will be of highest attention.

\subsection{Findings of the Data Collected from Questionnaire}

Of the 24 questionnaires sent out via paper, all were returned, a return rate of $100 \%$.The data justify the fundamental philosophy of constructivism: the growth of knowledge is the result of individual constructions made by the learner's understanding [18], and learning is a socially interactive process rather than the independent and separate individual activity [2], for the data collected and ana- 
lyzed can be summarized as follows:

- Teacher and teaching methods are regarded as very important factors in their learning, but they are not the sole source of knowledge. Individual experiences, interpersonal communication and reflection also generate and internalize learning (see Table 2).

- An interactive way is preferred to begin their class, and the direct or didactic way of knowledge impartment is of no interest at all. They expect themselves to gain communication skills, especially their speech-delivering ability. Class discussion and peer dialogue are very valuable to them, which can be interpreted that they desire to share their understanding and will be more engaged if their opinions are valued and accepted. Therefore, they prefer their teachers not to give them direct answers to their puzzles; instead they prefer to find themselves in group discussion and literature reading (see Table 3).

- Teachers are more expected to play the role of a leader and role model in the classroom with competencies such as empathy, motivation, flexibility and vision (see Table 4).

The data demonstrated that students' preference over active learning while they are more passive in their learning at present. Constructivist teaching pedagogies and models are feasible to them, because even though they know nothing

Table 2. Students' preference ranking of sources of knowledge and skills.

\begin{tabular}{ccccccc}
\hline & 1 st & 2nd & 3 rd & 4 th & 5 th & 6 th \\
\hline books & 2 & 2 & 7 & 3 & 2 & 5 \\
life experience & 12 & 7 & 3 & 1 & 0 & 1 \\
$\begin{array}{c}\text { reflection } \\
\text { crude data }\end{array}$ & 4 & 4 & 2 & 5 & 4 & 3 \\
communication & 1 & 3 & 2 & 6 & 6 & 6 \\
having class & 2 & 6 & 4 & 4 & 6 & 1 \\
\hline
\end{tabular}

Table 3. Students' preferred learning activities.

\begin{tabular}{ccccccccccc}
\hline & 1 st & 2 nd & 3 rd & 4 th & 5 th & 6 th & 7 th & 8 th & 9 th & 10 th \\
\hline Instructions & 7 & 3 & 2 & 3 & 1 & 2 & 1 & 1 & 2 & 0 \\
Task Assignment & 2 & 2 & 1 & 1 & 2 & 1 & 2 & 3 & 1 & 7 \\
Discussion & 7 & 5 & 4 & 2 & 1 & 1 & 1 & 1 & 1 & 1 \\
Group work & 1 & 4 & 4 & 3 & 4 & 3 & 2 & 2 & 0 & 0 \\
Brainstorming & 4 & 1 & 5 & 2 & 0 & 3 & 3 & 0 & 4 & 0 \\
Reflection & 0 & 1 & 2 & 3 & 3 & 0 & 2 & 1 & 2 & 3 \\
Seminar & 0 & 2 & 1 & 2 & 1 & 2 & 3 & 4 & 5 & 2 \\
Presentation & 1 & 0 & 0 & 3 & 4 & 2 & 7 & 3 & 0 & 3 \\
Debate & 0 & 2 & 1 & 1 & 3 & 5 & 2 & 2 & 4 & 1 \\
Self-Study & 1 & 1 & 1 & 4 & 1 & 1 & 1 & 4 & 2 & 3 \\
\hline
\end{tabular}


Table 4. Students' expectations for teachers in their learning.

\begin{tabular}{cccccccc}
\hline & 1 st & 2 nd & 3 rd & 4 th & 5 th & 6 th & 7 th \\
\hline Leader & 7 & 5 & 1 & 2 & 3 & 2 & 3 \\
Role model & 9 & 5 & 3 & 3 & 2 & 1 & 0 \\
Host & 2 & 0 & 3 & 4 & 4 & 3 & 7 \\
Judge & 2 & 3 & 4 & 5 & 3 & 4 & 2 \\
Coach & 1 & 4 & 5 & 2 & 8 & 2 & 1 \\
Parent & 1 & 5 & 4 & 4 & 2 & 4 & 1 \\
Servant & 2 & 1 & 0 & 1 & 2 & 4 & 10
\end{tabular}

about constructivist learning, their inclination to a more communicative and interactive way of learning than the surface memorization and the fixed traditional way of knowledge impartment, and their value of life experience to their knowledge acquisition justify the fundamental principles of Constructivist teaching. On the other hand, their heavy reliance on teacher as their role model and leader in their learning, and their disinterest in reading, reflection and paper-based assignment indicate their low initiative in both basic knowledge accumulation as well as in-depth thinking. Therefore, the barriers numerous predecessors encountered emerge in the path to Constructivist teaching too.

\subsection{Findings of the Data Collected from Interviews}

"Knowledge is always gained through action and for action. From this starting point, to question the validity of social knowledge is to question, not how to develop a reflective science about action, but how to develop genuinely well-informed action how to conduct an action science" [19]. From the data gathered from questionnaire and interview, we can have a big picture on both students' and teachers' side, which helps me move one step closer to begin constructivist teaching

For students, their desired learning model is to be interactive and communicative: they can express their opinions and challenge teachers' views; they can participate in group discussions, brainstorms; they can have more sources of knowledge and skills rather than solely textbooks; they can find answers themselves instead of direct answers given by teachers. Their homework or assignment can be collective and interesting but not paper-based. Their teachers can be flexible, empathic, motivating and visionary as leaders and role models.

For teachers, the first concern to their students is their preliminary knowledge base, without which, any pedagogical practice can be unworkable; secondly, applying theory into practice is crucial and many learning activities can be adopted to make it happen, especially collective participation; thirdly, classroom management is important. In order to guarantee teaching effect, teachers must take disciplinary control into serious consideration, which in turn, requires teachers to prepare actively to cope with; fourthly, teacher plays a very important role in 
the teaching, ranging from creating friendly environment to get students involved into various learning activities, to provide more sources of knowledge and skills, to invite students' understanding before sharing correct answer, to deepen students' understanding by challenging peers' or even teachers' ideas, and finally to be able enough to control the teaching and learning process.

Moreover, two interviews, to some extent, do offer some hints to my questions mentioned above. To boost students' autonomy and initiative in learning, group work with collective participation, especially initiated by the student leaders, is a good way. To deepen students' thinking, preparing probing questions and designing task-based or project-based activities are two practical ways. To handle the balance between flexible learning and orderly classroom management, creating a supportive learning environment outweighs disciplinary issues, which can be tackled by teachers' intentional interventions and students' self-management in the learning community [20].

\section{Conclusions and Implications}

The gap between the dream and reality is quite obvious. Compared to constructivist teaching criteria [5], teaching of interviewees still falls into traditional category: the learning taking place in our classroom is not so active, for it seems not so successful in constructing knowledge rather than imparting knowledge; the interaction between students to teachers, students to peers do happen but not enough; the learning is more conceptual than contextual because of the limited learning materials and low connection between new and prior knowledge; chances are inadequately given to reflect or guide students how to reflect; students' learning autonomy, to some extent, is admitted and valued, but not enough; the learning activities in class are not so diversified and effective; more collective group work should be encouraged to deepen their understanding and learning.

Although the research is based on a small sample, it helps inspire teachers how to start and then take small steps to begin constructivist teaching with some implications:

- Teacher, as an important factor in students' learning process, first should be aware of the roles he/she plays in knowledge construction. He/she is expected to support the learners' understanding and learning instead of transmitting the information to the learners. Therefore, I should trust my students with more assurance that they can learn actively and effectively. To lower the concern of discipline, more chances should be supplied to engage them to discuss and share.

- Teaching is a learning-teaching process rather than a teaching-learning tradition, which stresses that the learner should be placed first and should be the center of the learning practice. Considering the fact that students could be anxious, for they are not learning enough for the exams, text-books can be chosen in sections to serve the purpose. Summarizing each session of learning is of vital importance because it checks students' past learning and facili- 
tates the happening of new learning.

- Students' learning autonomy should be highly considered and respected in constructivist learning. To do so, students' interest, leadership, cooperation, team work, presentation and even questioning should be encouraged and invited. Way of boosting students' learning can be borrowed, especially the students' leadership.

- Reflection as a useful tool to deepen thinking should be cultivated and taken habit both inside and outside the classroom. Teachers can lead students to reflect and showcase their reflection. If teachers can spare some time, maybe just five or ten minutes for them to think carefully and quietly what they have learnt and how they feel about it after their learning and encourage them to share their learning experience with each other, then a reflective summary can be assigned for revision.

- Teaching materials can be multiple. Besides designated textbooks, hands-on materials are also very useful. Students' experiences, ideas, inventions and predictions should be given considerable attention. I should offer more hands-on materials or real-life materials to evoke their interest and to deepen their thinking.

- In terms of classroom management, constructivist teaching may cause temporary disorder, but in a long run, with the help of student leadership, it will be improved and solved. So disciplinary disorder is not that horrible and with guidance, good habits as well as supervision, it can be under control on the right track.

- Cooperative teaching strategy should be adopted through students' interactions and mutual respect, sharing ideas and learning tasks. Students' sharing sometimes is more effective than direct instruction, so in my future teaching, cooperative learning can be more involved.

- It is necessary for a teacher to pay special attention to the four emotional intelligences, which students demand: vision, flexibility, motivation and empathy. Being constructivists, teachers' vision is to strike the delicate balance between teaching for fact and skill acquisition and teaching for independent and expert thinking [21]. The calls for flexibility can be interpreted in three ways: 1) a highly adaptable and altered teaching style; 2) the differences or the gaps in the aspect of both academic abilities and learning methods between individual learners; 3 ) varied resources of knowledge leads to varied and unfixed learning experiences. Built on the philosophy that every student is an active learner who constructs their knowledge on their experience, constructivist teachers with motivation first view it their responsibility to build a good learning climate to motivate the students to achieve by learning. Empathy has two-fold implications to teachers: first, the teachers themselves should have the empathy for their students so as to teach effectively and affectively; second, teachers should teach this skill to the students.

To be a Constructivist teacher, challenges always exist. How to facilitate students' learning by formative assessment is worth further attention. Besides, how 
to create a constructivist classroom that supports active learning is also a long-discussed issue. How to implement Five Es Model [10] successfully in Constructivist teaching still demand specification in future teaching.

Beliefs are the bedrock and cornerstone at the heart of our actions [5]. Beliefs of a teacher are fundamental and instrumental in deciding teaching approaches, information related to the teaching tasks. To get prepared for Constructivist teaching, expertise, effort, commitment, competencies are required [6].

\section{Conflicts of Interest}

The author declares no conflicts of interest regarding the publication of this paper.

\section{References}

[1] Duffy, T.M. (2014) Constructivism: Implications for the Design and Delivery of Instruction. Journal of Education and Training Studies, 3.

[2] Vygotsky, L.S. (1978) Mind in Society. Harvard University Press, Cambridge, MA.

[3] Abbdal-Haqq, I. (2018) Constructivism in Teacher Education: Considerations for Those Who Would Link Practice to Theory. Clearinghouse on Teaching and Teacher Education, Washington DC.

[4] Prawatt, R.S. (2012) Instructors' Beliefs about Teaching and Learning: A Constructivist Perspective. American Journal of Education, 100, 354-395. https://doi.org/10.1086/444021

[5] Muijs, D. and Reynolds, D. (2015) Effective Teaching: Evidence and Practice. $3^{\text {rd }}$ Edition, SAGE Publications, London.

[6] Cey, T. (2011) Moving towards Constructivist Classrooms. University of Saskatchewan, Saskatoon.

[7] Kim, J.S. (2015) The Effects of a Constructivist Teaching Approach on Student Academic Achievement, Self-Concept, and Learning Strategies. Asia Pacific Education Review, 6, 7-19. https://doi.org/10.1007/BF03024963

[8] Schreiber, L.M. and Valle, B.E. (2013) Social Constructivist Teaching Strategies in the Small Group Classroom. Small Group Research, No. 2, 1-17. https://doi.org/10.1177/1046496413488422

[9] Baviskar, S.N., Hartle, R.T. and Whitney, T. (2009) Essential Criteria to Characterize Constructivist Teaching: Derived from a Review of the Literature and Applied to Five Constructivist-Teaching Method Articles. International Journal of Science Education, 31, 541-550. https://doi.org/10.1080/09500690701731121

[10] Bailey, K.D. (2004) Methods of Social Research. 6th Edition, The Free Press, New York.

[11] Boddy, N., Watson, K. and Aubusson, P. (2003) A Trial of the Five Es: A Referent Model for Constructivist Teaching and Learning. Research in Science Education, 33, 27-42. https://doi.org/10.1023/A:1023606425452

[12] Lord, T.R. (1997) Comparing Traditional and Constructivist Teaching in College Biology. Innovative Higher Education, 21, 197-217.

https://doi.org/10.1007/BF01243716

[13] Dharmadasa, I. (2010) Teachers' Perspectives on Constructivist Teaching and Learning. The Annual Conference of Association for Childhood Education Interna- 
tional, Baltimore, Maryland.

[14] Petraglia, J. (2008) The Real World on a Short Leash: The (Mis)application of Constructivism to the Design of Educational Technology. ETR \& D, 46, 53-65. https://doi.org/10.1007/BF02299761

[15] Scott, D. and Morrison, M. (2005) Key Ideas in Educational Research. Continuum International Publishing Group, London.

[16] Chaille, C. and Britain, L. (2001) Young Child as a Scientist: A Constructive Approach to Early Childhood Science Education. Harper Collins, New York.

[17] Flinders, D.J. (1997) Review of the Book InterView: An Introduction to Qualitative Research Interviewing. Evaluation and Program Planning, 20, 287-288. https://doi.org/10.1016/S0149-7189(97)89858-8

[18] Piaget, J. (1976) To Understand Is to Invent: The Future of the Education. Penguin Books, New York.

[19] Torbert, W.R. (1981) Why Educational Research Has Been So Uneducational: The Case for a New Model of Social Science Based on Collaborative Inquiry. In: Reason, P. and Rowan, J., Eds., Human Inquiry, Wiley, New York, 141-152.

[20] Parsole, E. and Leedham, M. (2009) Coaching and Mentoring: Practical Conversation to Improve Learning. 2nd Edition, Kogan Page, London and Philadelphia.

[21] Hook, P. and Vass, A. (2006) Confident Classroom Leadership. David Fultion Publishers, London. 